TITLE:

\title{
HAPLOSTOMELLA HALOCYNTHIAE (FUKUI), AN ASCIDICOLID COPEPOD ASSOCIATED WITH A SIMPLE ASCIDIAN, HALOCYNTHIA RORETZI (DRASCHE), FROM JAPAN
}

\section{AUTHOR(S):}

Ooishi, Shigeko; Illg, Paul L.

\section{CITATION:}

Ooishi, Shigeko ...[et al]. HAPLOSTOMELLA HALOCYNTHIAE (FUKUI), AN ASCIDICOLID COPEPOD ASSOCIATED WITH A SIMPLE ASCIDIAN, HALOCYNTHIA RORETZI (DRASCHE), FROM JAPAN. PUBLICATIONS OF THE SETO MARINE BIOLOGICAL LABORATORY 1974, 21(5-6): 365-375

\section{ISSUE DATE:}

\section{4-12-23}

URL:

http://hdl.handle.net/2433/175875

RIGHT: 


\title{
HAPLOSTOMELLA HALOCYNTHIAE (FUKUI), AN ASCIDICOLID COPEPOD ASSOCIATED WITH A SIMPLE ASCIDIAN, HALOCYNTHIA RORETZI (DRASCHE), FROM JAPAN
}

\author{
SHIGEKO OOISHI \\ Faculty of Fisheries, Mie University, Tsu, Mie, Japan \\ and \\ PAUL L. ILLG \\ Department of Zoology, University of Washington, Seattle, Washington, U.S. A. \\ With Text-figures 1-3 and Plate XI
}

Although the original description and illustrations of Rhabdomorpha halocynthiae by Fukui (1965) do not allow detailed comparison, they have given interesting ecological and taxonomic problems to the present authors because the species, which is a dweller in a solitary ascidian, is shown as bearing 9 pairs of appendages between the head and the caudal rami, although its characteristic vermiform habitus is like that of haplostomins (from his figures). In general, in the haplostomins (Subfamily Haplostominae Chatton \& Harant, 1924b), which are mostly associates of compound ascidians, the post-head appendages consist of 4 or 5 thoracic pairs. The poorly known subfamily includes 4 related genera, Haplostomides, Haplostoma, Haplosaccus, and Haplostomella. The last genus will now include 5 species, H. magellanica (Chatton \& Brément), 1910, from the Straits of Magellan and the Mediterranean, H. malacocera Chatton \& Harant, 1924a, H. tuberculata Chatton \& Harant, 1924a, from the Mediterranean, H. sycozoae (Salfi), 1926, which has been referred to this genus by Gotto (1959), from South America, and $H$. australiensis Gotto, 1970, from Australia. The present form thus is a second Haplostomella species from the gut of a solitary ascidian from the Indo-Pacific, in addition to $H$. australiensis.

We wish to express our hearty thanks to Dr. Satoru Kamegai, director of Meguro Parasitological Museum, for providing us the opportunity to examine Dr. Fukui's specimens before we acquired the present material. We are indebted to Mr. Hiroshi Onodera, director of Miyagi Prefectural Fisheries Experimental Station, for his kindness in facilitating the collection of the ascidians. The authors' thanks are also due to Mr. Hojiro Kikuchi, Mr. Tomio Ito and Mr. Yoshihiko Kadoma, who are members of the staff of that station, for their cooperation in collecting.

Publ. Seto Mar. Biol. Lab., XXI (5/6), 365-375, 1974.

(Article 23) 


\section{Haplostomella halocynthiae (Fukui)}

Synonymy : Rhabdomorpha halocynthiae Fukui, 1965.

Material : 21 females ( 7 females ovigerous), from intestines of 90 specimens of Halocynthia roretzi (Drasche) from ascidian culture beds (PL. XI, Fig. 1), Ogati Bay (PL. XI, Fig. 3), Miyagi Prefecture, Japan, $38^{\circ} 30^{\prime}$ N., $141^{\circ} 29.5^{\prime}$ E., July 3-4, 1972 . The type material of Dr. Fukui was also examined. From our material several specimens of uniform size were dissected to make the redescription and the drawings presented below.

Redescription: Female: The body (Text-Fig. 1a, b, c, PL. XI, Fig. 2) is elongate and subcylindrical, of vermiform appearance. The average length of the body, from the tip of the cephalosome to the end of the caudal rami, is $10 \mathrm{~mm}$. The body is not clearly segmented but subdivision is indicated by indentations and also by internal muscle strands and features of their arrangement. Thus it is indicated as roughly divided into 3 divisions of cephalosome, metasome and urosome, with their proportional lengths, anterior to posterior, about $1: 10: 4$. The average maximum width is $1 \mathrm{~mm}$; the widest point of the body occurs between the second to fourth leg-bearing segments. The proportional greatest width, measured on each part of the cephalosome, metasome and urosome, are about $0.7: 3: 2$. The paired egg strings are hung from the oviducal apertures which are dorso-laterally located approximately at the upper fifth of the urosome. Each string, about $4 \mathrm{~mm}$ in length, is elongate and fusiform, packing relatively small embryos within its tough wall; the posterior half extends beyond the end of the body. On the whole, the body shows a slight dorsal curvature on the metasome, while the tip of the urosome, including the caudal rami, is slightly directed ventrally. The color of the body is a transparent orange, with the eye brown, the gut orange, and ova dark brown. All the appendages except the caudal rami lack clear articulation on the body proper. The ventral face of the relatively small cephalosome (Figs. 1d, $2(-n)$ is anteriorly directed, and bears the following paired appendages: antennules, antennae, mandibles; maxillules probably are indicated by small protuberances; maxillae, and maxillipeds. The cephalosome is furnished anterodorsally with an $\mathrm{H}$-shaped sclerotized cephalic plaque (Fig. 1e) with distinctly set off semicircular postero-lateral margins. It is meagerly ornamented with minute hairs which arise from the centers of mammiform projections. The metasome shows indication of composition of 5 segments, bearing 5 pairs of legs. In correspondence to the ventral position of the legs each segment carries a pair of doro-lateral plates of suboval outline (Text-Figs. 1a, 3z,

Text-Fig. 1. Haplostomella halocynthiae (Fukui), female: a, habit, dorsal, overall length $10 \mathrm{~mm}$; $b$, same, ventral ; $c$, same, lateral; $d$, oral area; e, apical plaque; $f$, urosome, ventral ; $\mathrm{g}$, probably genital opening; h \& $\mathrm{i}$, sclerotized spots overlying joints of internal muscle strands; scales accompanying Figures $\mathrm{d}-\mathrm{i}$ represent $0.1 \mathrm{~mm}$.

Key to abbreviations : $A 1$, antennule ; $A 2$, antenna ; L, labrum; LI, labium ; MD, mandible ; MX, maxilla ; MXL, maxillule ; MXP, maxilliped ; PL, postoral lobe ; PS, postoral swelling. 


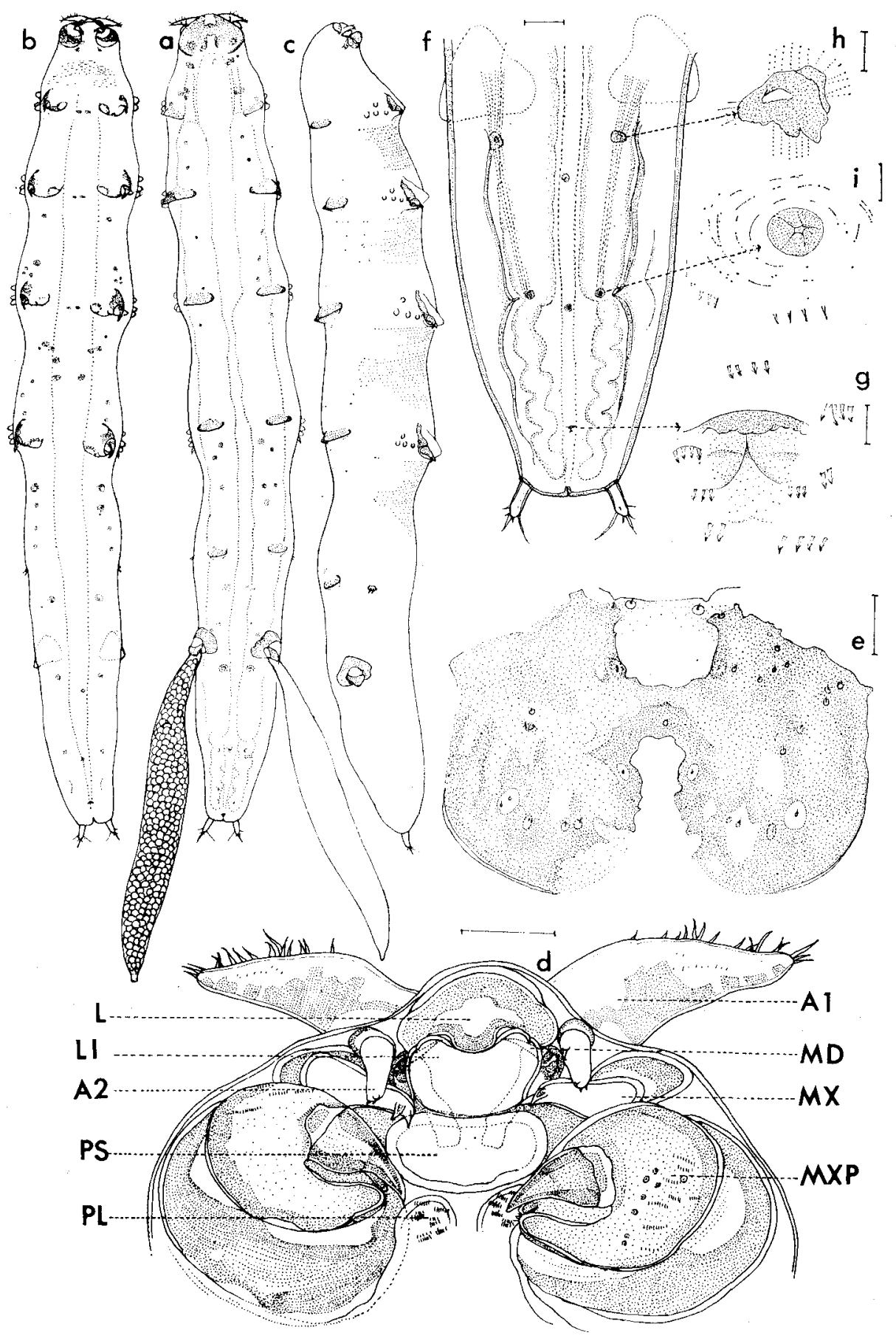


$\left.d^{\prime}, f^{\prime}\right)$; the plates on the fifth segment are the smallest in size. Their proportional widths from first to fith are about $11: 12.5: 13: 11: 6.5$. Each plate is wider than long and the free margin has a distinctive border of regular, subequal, incision-like markings, producing a somewhat laciniate effect. The outer surface of each is sparsely set with minute hairs which arise from mammiform projections. Distinctly arranged lateral groupings of 4 tubercles each are placed near the insertions of the first 4 pairs of limbs (Text-Figs. 1c, 3y, a'), lying between the limbs and the corresponding dorsal plates. Both the cuticular structures of the plate and of the group of tubercles are connected with the corresponding limbs by some muscle strands which adhere to the body wall internally. The metasome is followed without articulation by the gradually tapered urosome, the distal end somewhat truncated, with the anus opening as a tiny slit postero-dorsally. The caudal rami (Text-Fig. 1f) are set laterally and thus somewhat widely apart on the blunt end of the urosome. The oviducal apertures (TextFigs. 1a, c, 2j, k) involve conspicuous sclerotized cuticular structures and in each there is a swollen fold covering the actual oviducal opening, with a subtriangular marginal plate surrounding the fold and opening. The fold is articulated with the inner anterolateral margin of the plate and connected with its inner ventral margin. The under surface of the fold (Text-Fig. $2 \mathrm{k}$ ) is equipped with a transverse row of 3 strong teeth and a tooth-like marginal projection posteriorly. There is no sclerotized dorsal area between the paired oviducal structures, but there are some internal muscle strands. The oviducts (Text-Fig. 1a) appear to lie along either side of almost the entire length of the gut. On the ventral side of the anterior urosomal area supporting the abovementioned structures there is neither a conspicuous insemination pore nor any diverging tubes. However, a small central pore-like structure (Text-Fig. 1b, f, g) found ventrally well back from the position of the oviducal apertures may be the insemination pore, although there is doubt about its identity. The thick body wall is sculptured by minute transverse flexures and covered with many rows of several denticles (Text-Fig. $1 \mathrm{~g}$ ) along the latero-ventral surface as well as with single denticles on the dorsal side. Behind the cephalosome, small sclerotized spots (Text-Fig. 1a, b, h, i), perceptible on the body surface, mark joints of internal muscle strands, mostly symmetrically arranged, running between the limbs or through the body. Between the spots there are often found symmetrically placed longitudinal grooves (Text-Fig. 1f).

The antennule (Text-Figs. 1d, 2p) is conical, with several characteristic sclerotized areas on the surface. The appendage bears about 17 short marginal setae as well as

Text-Fig. 2. Haplostomelia halocynthiae (Fukui), female : j, oviducal aperture, right, lateral; $\mathrm{k}$, fold over oviducal aperture, inside; 1 , oral area, antero-ventral; $m$, same, showing sites of mouthparts after removing antennae, maxillae \& maxillipeds, ventral; $n$, oral area, latero-ventral; o, same, showing mandible and maxillule after removing antenna, maxilla \& maxilliped, lateral ; p, antennule, left, posterior ; q, antenna, right, anterior, somewhat lateral; r, mandible, right, posterior;s, maxilla, right, anterior; $t$, same, apical projections, anterior ; $u$, same, posterior; scales accompanying Figures $j-q, s, u$, represent $0.1 \mathrm{~mm}$. 


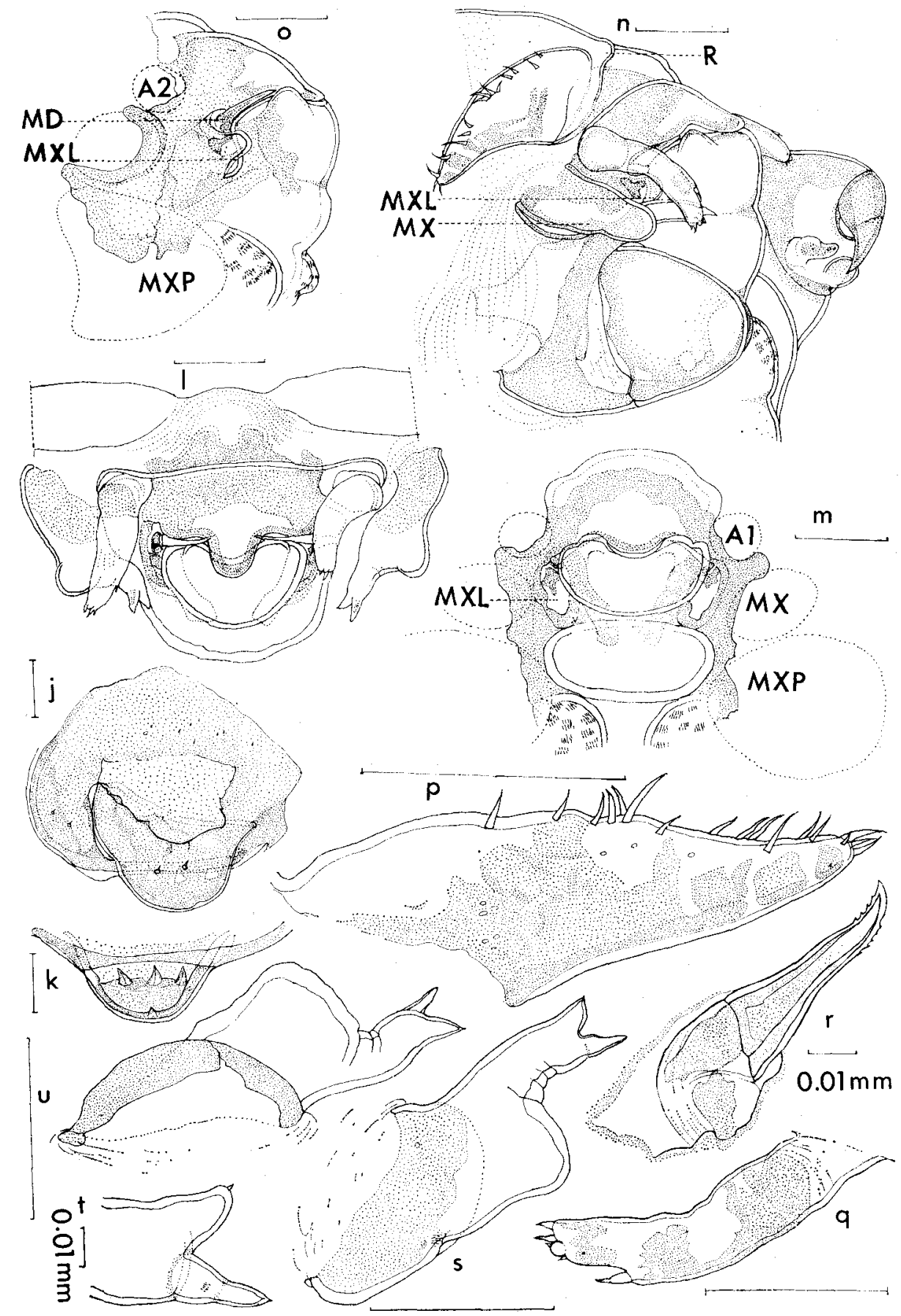


tiny hairs on the surface. There are no distinct indications of the possible segmental composition.

The antenna (Text-Figs. 1d, 2q) has a slightly curved, cylindrical appearance, with indication of division into 3 segments. The second segment is perhaps indicated by a small seta inserted at a marginal indentation possibly representing the medio-distal corner. The apex of the terminal segment is armed with 2 short setae somewhat lateral, and a medial setule arising from a round swollen base and accompanied by a fine setule.

The rostrum is not conspicuous but protrudes slightly ventrally.

The margin of the labrum has a marked medial convexity to correspond with the concave free border of the labium as shown in Text-Fig. 21 , o. The basal area of the former organ has a fold between the antennae. In the labium the swelling lateral border on either side has a slight groove at its middle (Text-Fig. $2 \mathrm{l}$ ).

The mandible (Text-Figs. $1 \mathrm{~d}, 2 \mathrm{l}, \mathrm{r}$ ) is reduced to a serrated spine arising from a base at the side of the mouth opening, between the labrum and labium and medially directed beneath the labrum.

The maxillule (Text-Fig. $2 \mathrm{~m}-0$ ) is indicated by, or greatly reduced to, a small integumental projection on a small sclerite behind the mandible and surrounded by an oval sclerotized framework. The lateral side of the membranous projection is ornamented with a few minute denticles. The entire structure is only visible after removal of the adjacent appendages.

The maxilla (Text-Fig. 1d, 2s) is a characteristic, elongate, unsegmented lobe which consists of a proximal broader and distal narrower portions. The distal portion, longer than wide, is cylindrical and medially extended from the distal-medial side of the subrectangular proximal portion. Therefore, the lateral margin of the lobe forms a step at the distal one-third accompanying a flexure between both portions. Similar flexures are found on the same side of the distal portion near the step. The distal portion (Text-Fig. 2t) is prolonged into 2 projections at the apex. The inner projection is terminally armed with a setule, while the outer, which is relatively stout and narrow, is tipped by a spinule. The smooth inner margin of the lobe comprising both distal and proximal portions is shorter than the outer margin of the proximal portion only. The posterior side of the proximal portion (Text-Fig. $2 \mathrm{u}$ ) is hollowed out in a semicircular articulation, which forms a heavily sclerotized margin, with the body wall.

The maxilliped (Text-Fig. 3v, w) is stout and massive, comprising 3 segments with somewhat perplexing articulations between them. The smallest, terminal segment

Text-Fig. 3. Haplostomella halocynthiae (Fukui), female : v, maxilliped, right, posterior; w, same, anterior; $x$, same, set of claw like projections, anterior; $y$, lst left leg with 4 lateral tubercles, antero-lateral; $z$, Ist left dorsal plate, anterior; a', 2nd left leg with 4 lateral tubercles, antero-lateral ; b', same, exopodite, posterior; $c^{\prime}$, same, seta representing basipodite; d', 2nd left dorsal plate ; $e^{\prime}, 5$ th left leg, anterior ; f', 5th left dorsal plate, anterior ; $g^{\prime}$, caudal ramus, left, dorsal ; scales accompanying Figures $v-z, a^{\prime}$, b', d', f', g' represent $0.1 \mathrm{~mm}$. 


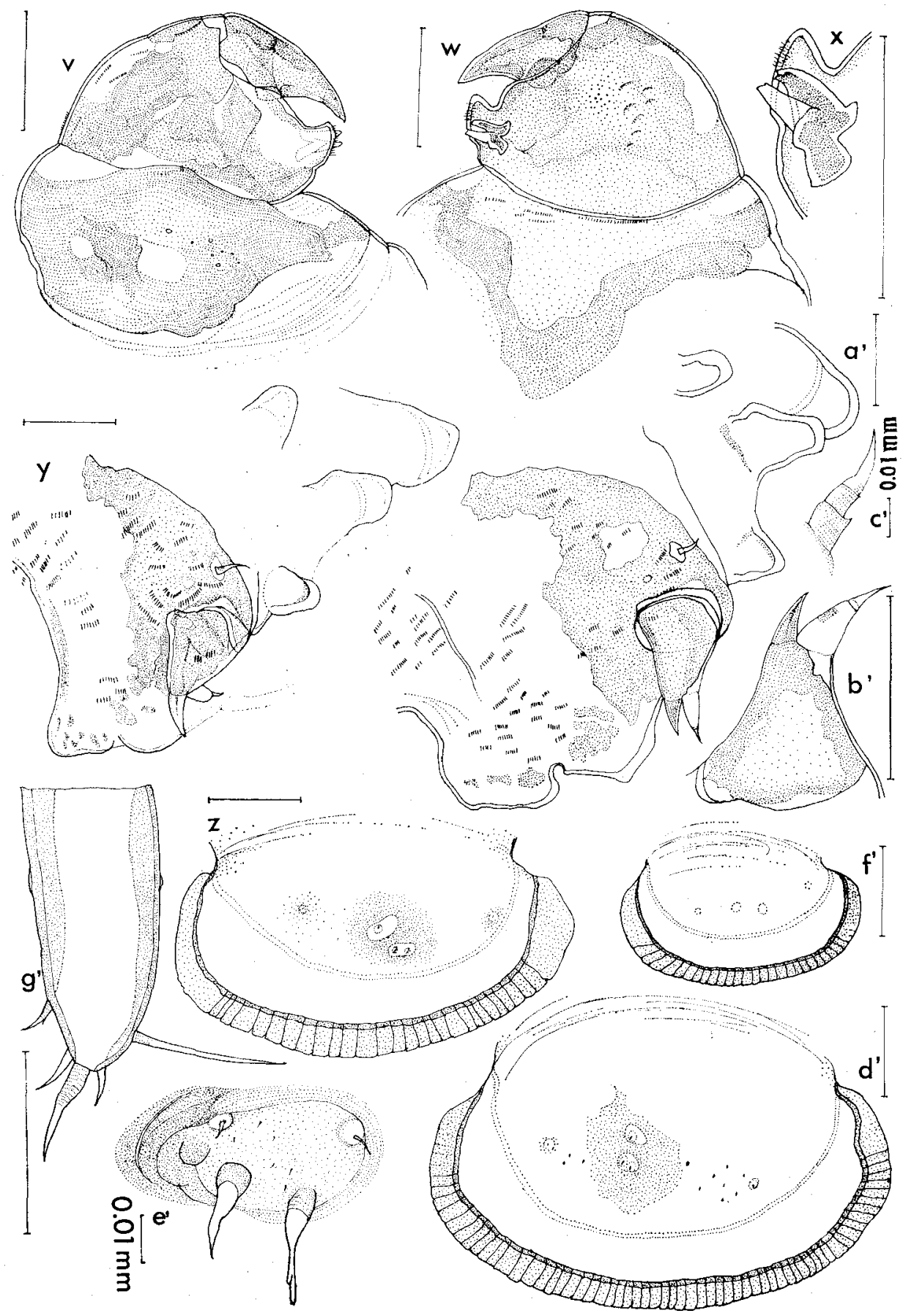


is fused with a heavy terminal claw. The second segment is much wider than long, and medio-distally it is protruded into a set of anterior and posterior claw-like processes, which provide a notch (Text-Fig. $2 n$ ) between them to meet the tip of the terminal claw. The anterior process divides into 2 spiniform projections at the apex; the posterior is characteristically modified, abruptly tapered anteriorly and with some hairs on its posterior round apex (Text-Fig. 3x). The posterior surface of the segment has sparse denticle rows and hairs arising from tiny mammiform projections. The proximal segment is remarkably depressed in the anterior side. The anterior surface of the segment has dentticle rows near the distal margin. In the proximal margin there is formed a sclerotized bar like the 2 sides of a triangle. The maxillipeds are inserted at both sides at the lateral limits of the postoral swelling (Text-Fig. 1d, PS). Behind the swelling there is a pair of conspicuous postoral lobes covered with striking denticle rows (Text-Fig. 1d, PL).

The first to fourth pairs of legs (Text-Figs. 1b, 3y, a') are almost alike in size and structure, with about the same proportional sizes as the latero-dorsal plates corresponding. The legs are situated near the posterior extents of their respective segments. The members of each pair are widely separated from each other without an intercoxal plate. The protopodite is not distinctly demarcated from the body surface nor into components but these are probably indicated by the sclerotized integument which is covered with denticle rows and hairs. Moreover, a lateral seta which is inserted near the base of the exopodite presumably refers to the basipodite. The proximal part of the seta (Text-Fig. 3c') is stout with 2 articles. The exopodite is unsegmented, heavily sclerotized and well articulated in a depression in the protopodite. The exopodite (Text-Fig. 3b') is divided into anterior and posterior lobules. The anterior lobule terminates in a slightly curved strong hook, whereas the posterior one, which is less sclerotized, is conically tapered, with an articulation somewhat beyond the midpoint; the apical piece has an almost setiform aspect. The endopodite is suggested by a bilobed bulging projection from the protopodite, ornamented by denticle rows.

The fifth leg (Text-Fig. 3e') is reduced to 2 stout setae, with sclerotized basal parts, these arising from a small, oval, plate-like, cuticularized area situated laterally on the last metasomal segment. The area bears sparse minute hairs and 2 setules arising trom mammiform projections.

The caudal ramus (Text-Fig. 3g') is small, conical and 2.2 times as long as the greatest width. It carries 5 setae in all:1 apical stout seta between 2 subterminal subequal short setae; 1 short medial seta at the distal fourth; and 1 lateral seta at the distal sixth.

The male is unknown.

REMARKS: Similar ecological and geographical conditions in the present species and H. australiensis appear to ally these forms closely taxonomically among the Haplostomella species; the relation is also indicated by the overall similarities in morphology, although a terminological problem with regard to the moutparts arises. We find $H$. 
halocynthiae to possess all normal mouth appendages, taking into account the extreme reduction of the maxillule; $H$. australiensis is described as lacking both maxillules and maxillae. However, the description and illustration of the so-called mandible of the latter species (Gotto, 1970, p. 270, Fig. 11) obviously conform with the maxilla of our species, in regard to position and morphological features. The appendage shown by Gotto has an expanded basal portion from which extends a smaller rectangular element with terminal seta and projection; the appendage is essentially the same in the two species. Similar terminological difficulties arise in the comparison of the present species to all the previously recorded species. The "mandible" of $H$. magellanica, $H$. sycozoae and H. malacocera, in which maxillule and maxilla were reported absent, and the "maxillule" of $H$. tuberculata, which was said to lack the maxilla, could all well apply to the maxilla of the present species. In $H$. tuberculata the mandible is identified by us from its structure and location, although the element is not spiniform but palplike with a small apical setule. We have full reason for this identification because the two types of spiniform (as in $H$. halocynthiae) and palp-like (as in $H$. tuberculata) mandibles are found among undescribed North American Haplostomella species which we have been studying (unpublished).

Generally, the embryology is useful for understanding the origin of crustacean appendages. Anderson and Rossiter (1969) have studied the embryology of H. australiensis. According to their statement, neither the copepodite stages nor the adult female show traces of maxillules or maxillae. However, as the study was done rather physiologically as to the larval stages from the newly hatched nauplius to the first copepodite, the statements and figures are insufficient in detailed morphological characterization of the appendages in each stage. In our North American species of Haplstomell a (unpublished studies) simplification of the naupliar mandible and acquisition of the second pair of mouthparts really fully formed, the maxillae, occur at the same time at the appearance of the first copepodite stage. We are therefore assuming that the complement of mouthparts and the developmental pattern is essentially the same in all the species of Haplastomella. We assume that close examination will reveal the mandible in the forms in which it has been stated it is lacking. It is possible that some or all of the species will also turn out to possess the rudiment of the maxillule, as seen by us. As previously stated, the maxillule is reduced but perceptible in its appropriate location by the existence of the membranous projection surrounded by the sclerotized oval framework. A similar sclerotized condition can be inferred in the figure of the oral area of $H$. malacacera (Chatton and Harant, 1924a, p. 365, Fig. 1-3), although no notice is given by the authors.

From both morphological and embryological points of view, we also conclude that the second conspicuous mouthpart in Haplostomella should refer to the maxilla. In this regard, as the head of species of this genus is directed considerably anteriorly and the appendages are not distinctly demarcated from the body surface, the insertion of the maxilla between the antenna and maxilliped, lateral to the mouth area, makes it appear 
near the antenna, as if it is the first mouthpart, as shown in Fig. 1d. This arrangement doubtless led to the confusion of various examiners in ascertaining the identity of the mouthparts.

The present form is readily distinguishable from $H$. australiensis by its large size (10 $\mathrm{mm}$ in $H$. halocynthiae, compared to $7 \mathrm{~mm}$ in $H$. australiensis), in having the urosome unsegmented (4-segmented in $H$. ausiraliensis), and possessing the maxilla with 2 smooth apical projections (one projection with a plumose seta in $H$. australiensis).

We note that the 9 paired appendages including 3 reduced pairs, as shown in $H$. halocynthiae by Fukui (1965, p. 62, Fig. 2) actually consist of the 5 paired limbs, the pair of oviducal apertures and accompanying apparatus, and 3 pairs of the many paired sclerotized spots to which muscle strands adhere internally in this form.

Ogati Bay, known as one of the most excellent places for culturing the edible ascidian Halocynthia roretzi, is in the Tohoku district of northern Japan. In our samples none of the ascidians was occupied by more than one female of Haplostomella halocynthiae. In his account of the new copepod Dr. Fukui referred to a second form, with a brood pouch. It is very likely this was an occurrence of Bonnierilla curvicaudata Ooishi, a rather frequent commensal in the pharynx of $H$. roretzi (see Ooishi, 1963).

\section{REFERENCES CITED}

Anderson, D. T. \& G. T. Rossiter, 1969. Hatching and larval development of Haplostomella australiensis Gotto (Copepoda, Fam. Ascidicolidae), a parasite of the ascidian Styela etheridgii Herdman. Proc. Linn. Soc., New South Wales, 93 (3):464-475.

Chatton, E. \& E. Brément, 1910. Sur trois ascidicoles du genre Aplostoma Canu:Aplostoma magellanica n. sp., A. hibernica (T. et A. Scott), A. sacculus n. sp.. Bull. Soc. zool. France, 35 : 80-92.

Chatton, E. \& H. Harant, 1924a. Notres sur les copépodes ascidicoles, 16. Le nouveau genre Haplostomella. Deux espéces nouvelles de ce genre. Remarques sur les oostégites et la $5^{\mathrm{e}}$ paire de péréiopodes. Bull. Soc. zool. France, $49: 364-372$.

-__ \& $1924 \mathrm{~b}$. Notres sur les copépodes ascidicoles, 18. Haplostoma canui n. sp.. État acturel de la systématique des Haplostominae n. subf. Le nouveau genre Haplosaccus. Bull. Soc. zool. France, $49: 378-387$.

Fukui, T. 1965. On some parasitic copepods of Japan. Kökakurui no Kenkyu (in Japanese). No. $2: 60-66$.

Gotto, R. V., 1959. The rediscovery in British waters of two little-known copepods. Irish Natural. Journ., $13(1): 9-11$.

- 1970. Haplostomella australiensis n. sp., an ascidicolous copepod from New South Wales. Crustaceana, 19 (3): 267-272.

Ooishi, S., 1963. On some notodelphyid copepods from the Bay of Kesennuma. Rept. Fac. Fish., Pref. Univ. Mie, $4(3): 377-389$.

Salfi, M., 1926. Su un nuovo copepoda ascidicolo del genre Aplostoma Canu. Ann. Mus. Zool. R. Univ. Napoli, $5(15): 1-4$. 


\section{EXPLANATION OF PLATE XI}

Fig. 1. A string of Halocynthia roretzi (Drasche) from an ascidian culture bed.

Fig. 2. Three specimens of Haplostomella halocynthiae (Fukui) in a dish.

Fig. 3. The ascidian culture beds in Ogati Bay. 
Publ. Seto Mar. Biol. Lab., XXI (5/6), 1974.

PLATE XI
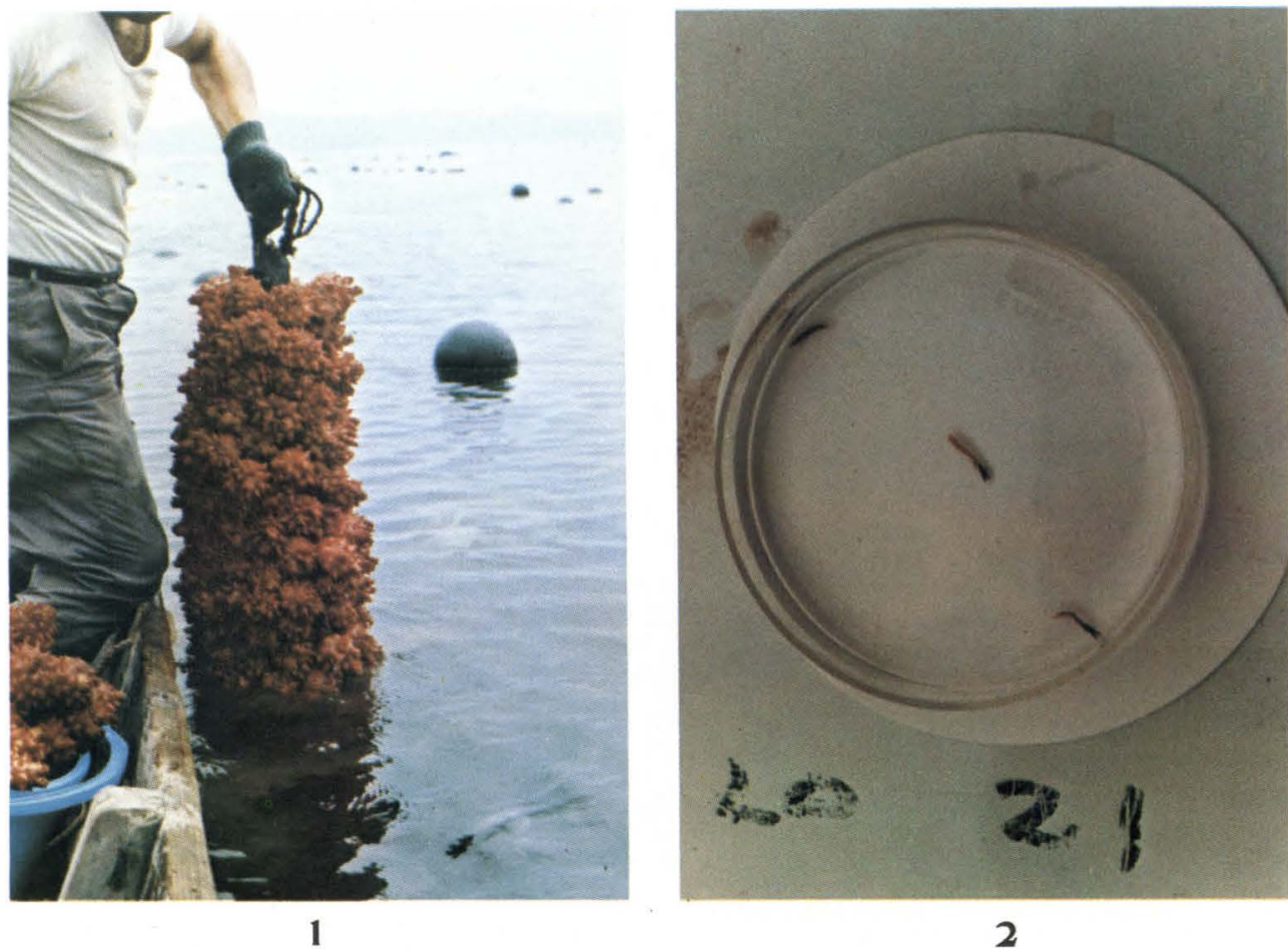

2

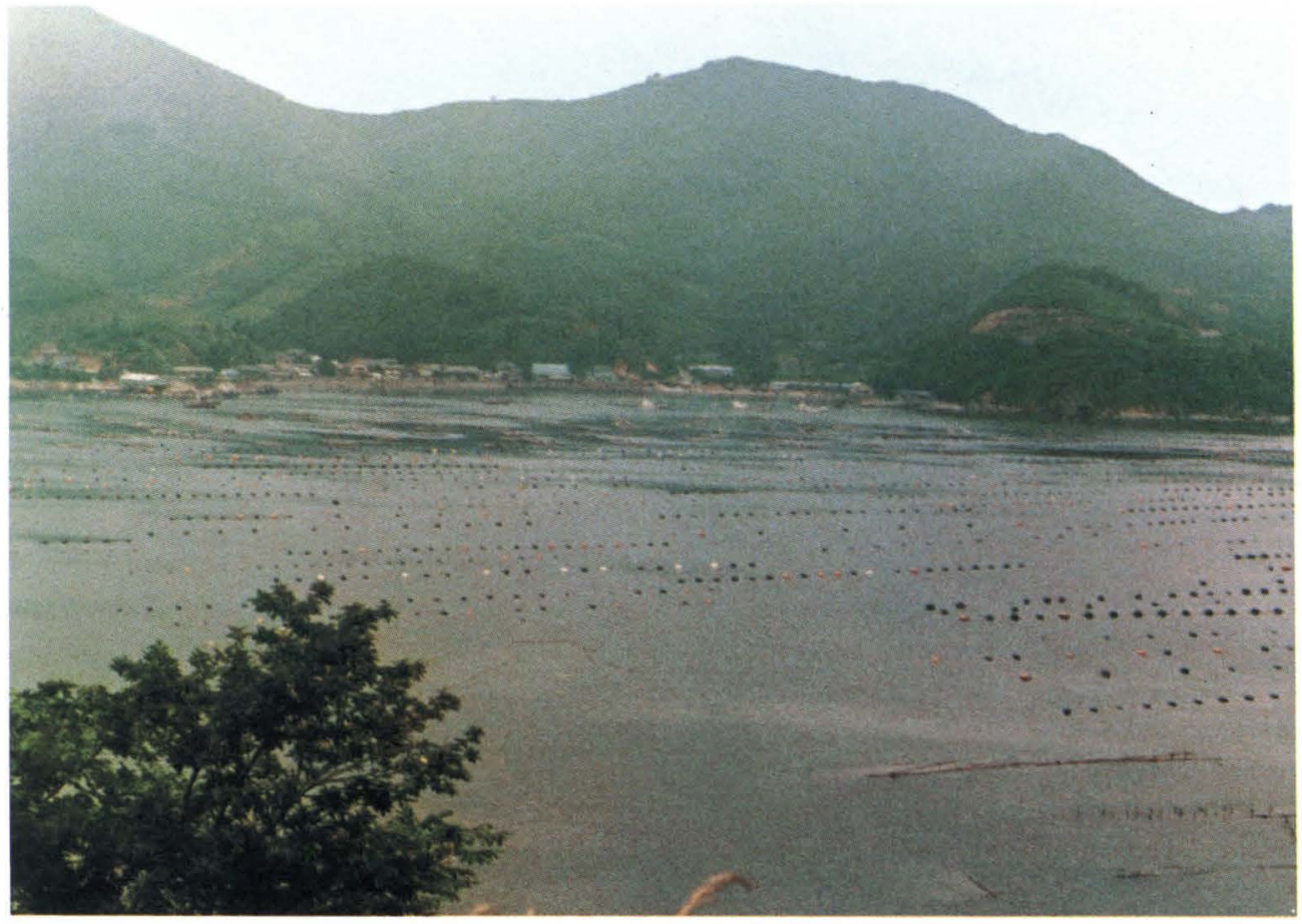

3

S. Oorshi \& P.L. Illg: Ascidicolid Copepod from a Simple Ascidian 